\title{
TEM Characterization of Phase Separation and Transformation at the Thin Film Interfaces in the $\mathrm{SrFeO}_{2.5+x} / \mathrm{SiO}_{2} / \mathrm{Si}$ System
}

\author{
Dashan Wang*, Xiaomei Du*, James J. Tunney*, Michael L. Post* and Raynald Gauvin** \\ *Institute for Chemical. Process and Environmental Technology, National Research Council of \\ Canada, Montreal Road, Ottawa, Ontario, Canada K1A 0R6 \\ **Dept of Min., Met. \& Mat. Eng., McGill University, Montreal, QC, Canada H3A 2B2
}

The electrical and gas sensing properties of the $\mathrm{SrFeO}_{2.5+\mathrm{x}}(0<\mathrm{x}<0.5)$ films are strongly dependent on cation and oxygen stoichiometries and on morphological structure [1]. Consequently, the interface thermal stability of the films is critical, in terms of diffusion, phase transformation and compositional uniformity of the films. A recent study of interfacial reactions between $\mathrm{SrFeO}_{2.5+_{\mathrm{x}}}$ thin films and $\mathrm{SiO}_{2} / \mathrm{Si}$ (where $\mathrm{SiO}_{2}$ is a preformed amorphous buffer layer) by pulsed laser deposition (PLD) techniques indicated that deposition at room temperature produces a film with a structure which is characterized as an amorphous film initiated on the $\mathrm{SiO}_{2}$ substrate, followed by the formation of nano-crystalline grains. This implied that the amorphous substrate provided a less favorable surface for the crystals to nucleate. The amorphous film and the nano-crystallites were shown to have been subjected to both growth and phase separation due to diffusion of Si through the interface as the temperature increased. A relatively discontinues layer of grains formed on the top surface and were embedded in an amorphous underlayer when deposited at $700^{\circ} \mathrm{C}$. Further annealing at this temperature resulted in a redistribution of $\mathrm{Fe}, \mathrm{Sr}$ and $\mathrm{Si}$ components across the film and a continuing of the phase separation [2]. Figure 1 schematically illustrates the changes in film thickness and interface structure at different deposition and heat treatment temperatures. In this study, the mechanism of diffusion-induced phase transformation of films in the $\mathrm{SrFeO}_{2.5+_{\mathrm{x}}} / \mathrm{SiO} 2 / \mathrm{Si}$ system deposited at $700^{\circ} \mathrm{C}$ was examined using Philips CM20 TEM and related techniques.

EDS analysis showed that silicon in the initially formed crystallites on the top surface was undetectable. However, significant amount of silicon was embedded in the amorphous phase underneath. The crystallographic structure of the film was identified by selected area electron diffraction, and shown to be cubic for the initially formed grains in contact with the amorphous phase of the film, and with a strong preferential orientation of [112] perpendicular to the film surface (Fig. 2a, b and c). The diffraction pattern from the outermost crystallites showed a strong diffraction ring indexed as (100), suggesting either a grouping of grains with a preferential orientation of [111] (Fig.2d) or that the initial crystallization of the film was affected by the structure and composition of the amorphous surroundings and subjected to change during growth (Fig. 2c).

Except for dissolution of $\mathrm{SiO}_{2}$ into the amorphous phase (denoted as $\mathrm{Sr}-\mathrm{Fe}-\mathrm{Si}-\mathrm{O}$ ) at the interface of $\mathrm{Sr}-\mathrm{Fe}-\mathrm{Si}-\mathrm{O} / \mathrm{SiO}_{2}$, further annealing of the film system at $700^{\circ} \mathrm{C}$ resulted in silicon diffusion and an induced phase transformation at the interface between $\mathrm{SrFeO}_{2.5+\mathrm{x}}$ crystal grains and the adjacent amorphous $\mathrm{Sr}-\mathrm{Fe}-\mathrm{Si}-\mathrm{O}$ phase to form a crystalline strontium iron silicate $\mathrm{Sr}_{2} \mathrm{FeSi}_{2} \mathrm{O}_{7}$. This is shown in Figure 3a as an indexed EDP along with HRTEM images of the silicate. The fact that annealing favors lateral crystallite growth which develops into a lamellar lattice structure facilitates identifying a mechanism of the phase transformation by examining the HR images. Figure $3 \mathrm{~b}$ indicates that the lamellar lattice structure of $\mathrm{Sr}_{2} \mathrm{FeSi}_{2} \mathrm{O}_{7}$ extends from the center of a previous grain through a transition zone between the grain center and the amorphous surroundings. Atomic rearrangement 
and crystal structure reconstruction can be viewed through the transition zone. The atomic arrangement for the lamellar structure is proposed as $(\mathrm{Fe}, \mathrm{Si}) / \mathrm{Sr} / \mathrm{Si} /(\mathrm{Fe}, \mathrm{Si})$ where $\mathrm{Si}$ atoms in $(\mathrm{Fe}, \mathrm{Si})$ substitute for Fe. Another type of atomic rearrangement in phase transformation appears to be due to the movement through the matrix phase towards the new phase in order to fill the atomic lattice steps at the interface plane of the new phase, as arrowed in Figure 3c. Thus the new phase grows by consuming the matrix phase. Basically, the lamellar lattice planes are both parallel and perpendicular to the film surface. This indicates the existence of two preferential orientations of the $\mathrm{Sr}_{2} \mathrm{FeSi}_{2} \mathrm{O}_{7}$ (Fig.3d). The structural effects of longer term annealing will also be presented.

\section{References}

[1] J.J. Tunney, P. Whitfield, X. Du, and M.L. Post, Thin Solid Films 42, 221 (2003).

[2] D.Wang, J.J. Tunney, X. Du, M.L. Post, R. Gauvin, Proceedings M\&M 2004, 572CD.

\begin{tabular}{|l|}
\hline $\mathrm{SrFeO}_{2.5+x}$ Nano-Crystal $[31 \mathrm{~nm}]$ \\
$\mathrm{SrFeO}_{2.5+\mathrm{x}}$ Amorphous $[15 \mathrm{~nm}]$ \\
\hline $\mathrm{SiO}_{2}[1.14 \mu \mathrm{m}]$ \\
\hline $\mathrm{Si}$ \\
\hline
\end{tabular}

\begin{tabular}{|l|}
\hline $\mathrm{SrFeO}_{2.5+x}$ (Crystal) $[15 \mathrm{~nm}]$ \\
\hline $\mathrm{Sr}-\mathrm{Fe}-\mathrm{O}-\mathrm{Si}$ Amorphous $[53 \mathrm{~nm}]$ \\
\hline $\mathrm{SiO}_{2}[1.13 \mu \mathrm{m}]$ \\
\hline $\mathrm{Si}$ \\
\hline
\end{tabular}

\begin{tabular}{|l|}
\hline $\mathrm{SrFeO}_{2.5+x}$ (Crystal) $[10 \mathrm{~nm}]$ \\
\hline $\mathrm{Sr}-\mathrm{Fe}-\mathrm{O}-\mathrm{Si}$ Amorphous $[40 \mathrm{~nm}]$ \\
\hline $\mathrm{SiO}_{2}[1.12 \mu \mathrm{m}]$ \\
\hline $\mathrm{Si}$ \\
\end{tabular}

Fig.1. Schematic illustration of the interfacial reactions in the $\mathrm{SrFeO}_{2.5+\mathrm{x}} / \mathrm{SiO}_{2} / \mathrm{Si}$ system. Films were deposited at RT (a); $700^{\circ} \mathrm{C}$ for 4 minutes (b); and with annealing at $700^{\circ} \mathrm{C}$ for 1 hour (c).
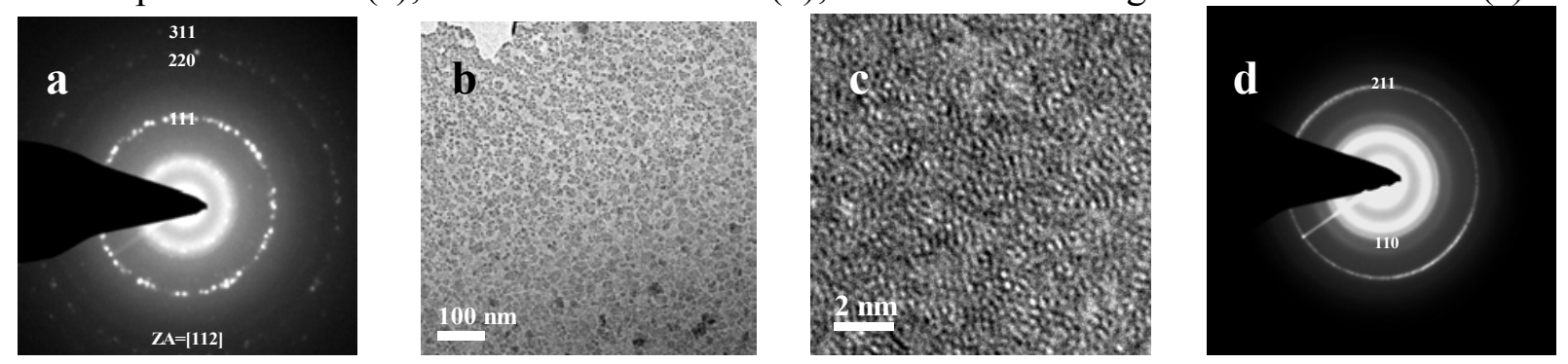

Fig.2. (a) SA diffraction patterns (DP) from the area shown in (b); a plan view TEM micrograph and the adjacent amorphous surrounding (c); DP from outmost crystallites of the film (d).
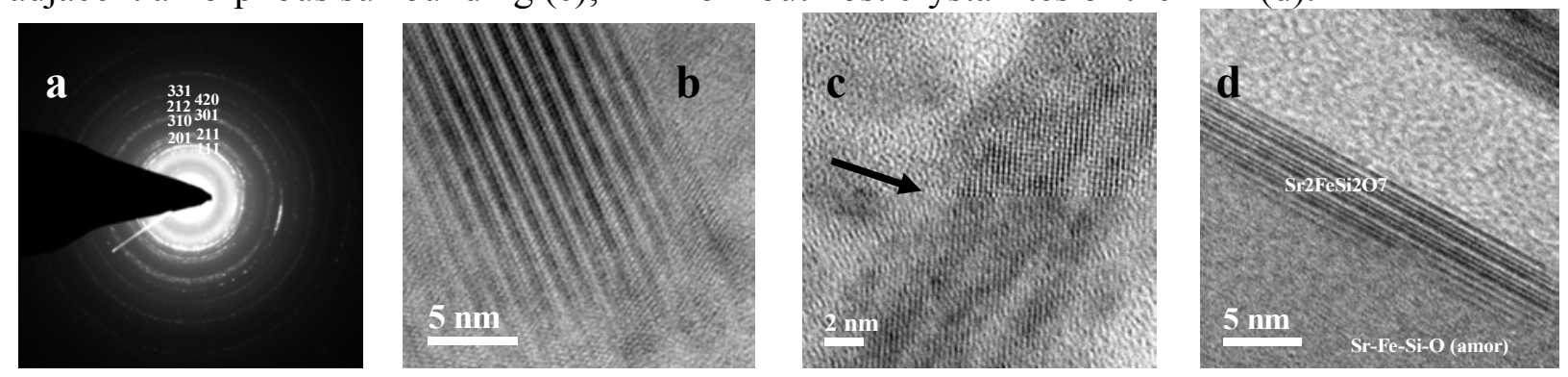

Fig.3. (a) a EDP from $\mathrm{Sr}_{2} \mathrm{FeSi}_{2} \mathrm{O}_{7}$; (b) and (c) plan view HRTEM images showing the phase transformation, and (d) a cross section HRTEM image showing the second orientation of the silicate. 